\title{
PRODUÇÃO DE TEXTO: EM BUSCA DA CONSTRUÇÃO DA AUTORIA
}

\author{
Luciani Dalmaschio* \\ Leania Magalhães Ursine*
}

RESUMO: Este trabalho surgiu da necessidade de lançarmos um olhar mais atento aos caminhos metodológicos percorridos pelo professor como mediador do processo da produção escrita dos alunos. Portanto, se organiza em torno do desenvolvimento de práticas relacionadas ao ensino de produção de textos a alunos da educação básica, por meio do trabalho com gêneros textuais. Dessa forma, objetiva realizar uma transposição didática dos pressupostos teóricos sobre produção textual, de modo a mobilizar o fazer pedagógico docente. Nesse sentido, trabalha com a perspectiva de que a mediação do professor é muito importante para que a voz do aluno-escritor apareça em sua escrita. O corpus em análise é composto por textos escritos e reescritos por alunos do oitavo e nono anos do ensino fundamental da Escola Estadual Brighenti Cesare, de São João del-Rei, MG, e fez parte das atividades da disciplina Prática Curricular Avaliação da Produção Escrita, oferecida pela graduação em Letras da Universidade Federal de São João del-Rei. A pesquisa teve como suporte teórico principal os estudos de Costa Val (2009) e Ruiz (2010) e como recorte de análise buscou refletir em que medida as propostas de redação aplicadas incentivam a subjetividade do aluno-escritor.

PALAVRAS-CHAVE: Construção de autoria; Ensino; Produção de texto.

\section{Introdução}

O texto é o espaço em que sujeitos, distanciados um do outro, podem marcar sua presença. (COSTA VAL, et.al, 2009, p. 70).

Não podemos negar que ensinar a escrever, a produzir textos que sejam percebidos como uma materialização significativa de efeitos de sentido pertinentes à vida social é um grande desafio. Um trabalho que lida com o desenvolvimento da escrita de alunos da Educação Básica traz constantes questionamentos que permeiam os planejamentos diários dos professores: o que propor para ser escrito? O que avaliar nas produções apresentadas? Como corrigir formalmente os textos produzidos?

\footnotetext{
${ }^{*}$ Doutora em Letras pela Universidade Federal de Minas Gerais (UFMG). Professora Adjunta da Universidade Federal de São João del-Rei (UFSJ) e coordenadora do Curso de Letras. É membro do grupo de pesquisa ENUNCIAR, da UFMG e Vice-Coordenadora do GT Semântica e Estudos Enunciativos da ANPOLL.

** Mestranda em Letras pela Universidade de São João del-Rei (USJR). Bolsista CAPES.
} 
De acordo com os postulados dos Parâmetros Curriculares Nacionais, quando retratam os objetivos gerais do ensino de Língua Portuguesa para o Ensino Fundamental, a escola deve organizar eventos de trabalho com a Língua que sejam capazes, dentre outros aspectos, de possibilitar a utilização da "linguagem na escuta e produção de textos orais e na leitura e produção de textos escritos de modo a atender a múltiplas demandas sociais, responder a diferentes propósitos comunicativos e expressivos, e considerar as diferentes condições de produção do discurso" (BRASIL, 1998, p. 32). Em um movimento teórico de reafirmação dessa perspectiva, a Base Nacional Comum Curricular - BNCC preconiza como um dos seus eixos aquele correspondente à produção de textos que "compreende as práticas de linguagem relacionadas à interação e à autoria (individual ou coletiva) do texto escrito, oral e multissemiótico, com diferentes finalidades e projetos enunciativos" (BRASIL, 2017, p. 76).

Não podemos negar que o ensino da produção de textos escritos na escola seja realizado. Entretanto, o que não podem deixar se vistas, também, são as lacunas que o resultado desse trabalho vem apresentando. Basta que observemos os índices que nos são explicitados pelos mais diversos instrumentos de avaliação nacionais e internacionais. Caso queiramos contestar a validade desses instrumentos - fato que consideramos pertinente para pesquisas futuras - podemos tentar realizar nós mesmos esse parecer. Todavia tememos, sob pena de estarmos muito pouco equivocadas, que, se analisarmos o texto dos alunos com os quais convivemos diariamente, encontraremos resultados cujos níveis de escrita serão, realmente, inferiores aos desejados.

Decorre desse fato nosso desconforto sobre essa questão. Não podemos naturalizar a perspectiva de que nossos alunos tenham dificuldade de escrita como se essa deficiência fosse algo imanente a esses estudantes. Resta, pois, impor a alguns fatos a importância que lhes é devida para uma análise mais complexa sobre o trabalho de produção de textos que deve ser realizado pela escola.

Escrever, assim como ler, pressupõe marcar-se subjetivamente por meio da linguagem. Logo, para que o aluno se coloque como sujeito do seu dizer, como autor, "ele tem de estabelecer uma relação com a exterioridade, ao mesmo tempo em que ele se remete à 
sua própria interioridade; ele constrói assim sua identidade como autor. Isto é, ele aprende a assumir o papel de autor e aquilo que esse papel implica" (ORLANDI, 1993, p. 78-79). Não podemos, portanto, transformar esse processo em um compromisso meramente formal e burocrático. Isso porque "a figura do Autor já é, na sua origem, paradoxal. Ao mesmo tempo que está na base de uma produção 'original', só se realiza dentro de um campo discursivo já cunhado e devidamente legitimado" (GALLO, 1992, p. 54), que é o campo da escola. E nesse espaço, infelizmente, “o que temos visto é a escalada, cada vez maior da 'escolarização' a todos os níveis de reflexão, reduzindo-se assim a vida intelectual a meros programas curriculares em que a preocupação maior está em parecer 'crítica"' (ORLANDI, 1993, p. 33).

É preciso, pois, que ocorra, no momento de produção de texto um processo de subjetivação. Em outras palavras, conforme Benveniste (1989), a língua prepara marcas para a entrada do sujeito. Logo, cabe a esse sujeito, entrar no aparelho formal da enunciação, individualizar-se e, ao mesmo tempo, assumir sua subjetividade, instalando o outro como seu interlocutor. Esse é, portanto, o papel da escola: propiciar essa passagem, fazer com que o aluno experimente práticas que o levem a controlar

os mecanismos com os quais está lidando quando escreve. Estes mecanismos são de duas ordens:

a) Mecanismos do domínio do processo discursivo, no qual ele se constitui como autor.

b) Mecanismos do domínio dos processos textuais nos quais ele marca sua prática de autor. (ORLANDI, 1993, p. 80)

De fato, então, a construção de autoria, exige muito do aluno, uma vez que

desde o primeiro momento em que o aluno se vê diante de uma situação de escrita até o último ponto que fecha seu texto, ele se vê obrigado a tomar decisões referentes a questões gerais (interpretar as circunstâncias daquela interlocução e os objetivos que pretende alcançar, definir o gênero de texto adequado) e os aspectos mais pontuais de estruturação do texto (colocar título, ou não, começar com 'era uma vez', ou não, usar o presente ou o pretérito, fazer frases curtas ou longas, empregar conjunções ou não, etc.)". (COSTA VAL, et. al, 2009, p. 71) 
Assim, os passos metodológicos que conduzem nossa pesquisa se ancoram no desenvolvimento de etapas da produção escrita, que permitem analisar: 1. A influência da proposta de produção na escrita dos estudantes, uma vez que, "em geral, o ato de produzir um texto decorre em grande medida de um ato de interpretação de uma proposta" (COSTA VAL, et. al, 2009, p. 72); 2. A necessidade de a avaliação contemplar forma e conteúdo, para que o dizer do aluno ganhe tanto relevo quanto o modo como foi dito; 3. A importância da delimitação de critérios de análise, de modo a oferecer destaque tanto à dimensão estrutural quanto à semântico-discursiva, características de cada gênero; 4. A interferência do tipo de correção a ser utilizado, na reescrita do aluno.

Embora neste texto tenhamos decidido apresentar apenas os resultados da primeira etapa do trabalho - A influência da proposta de produção na escrita dos estudantes -, pelo resultado geral da pesquisa, pudemos perceber que o ensino de produção de textos pressupõe uma rede de ações que, embora tenham que ser planejadas individualmente, precisam ser entrelaçadas para que o processo de escrita ganhe em complexidade e significação.

Passemos agora a fundamentar teoricamente os 4 passos descritos e, logo em seguida, a apresentar os resultados advindos da aplicação do primeiro deles.

\section{Qual a influência da proposta de produção na escrita dos alunos?}

Os processos de produção e de avaliação de textos envolvem uma interação marcada pela subjetividade, tanto do autor como do leitor. Desde a proposta textual feita pelo professor, ao selecionar esse ou aquele tema/esse ou aquele gênero; passando pela escrita do aluno, na qual ele dá forma às suas ideias e; por fim, durante a avaliação do professor, ao ler e fazer as correções que julga necessárias, a subjetividade está presente, margeando e conduzindo cada uma dessas etapas. Costa Val afirma que:

a subjetividade é um elemento inerente às atividades linguísticas de falar, ouvir, ler e escrever. Está sempre presente, embora limitada por condicionamentos linguísticos e sociais, e responde pelas opções, mesmo que não conscientes, feitas no momento da produção 
e da adoção de estratégias no momento da leitura [...] Essa atividade é subjetiva porque contém as marcas da história de vida, dos gostos pessoais e das representações de cada sujeito sobre a situação de interlocução. (COSTA VAL, et. al, 2009, p. 67)

Há, portanto, uma intersubjetividade envolvendo o diálogo que se estabelece entre o autor e o leitor no processo textual. Costa Val nos diz que "quem escreve, escreve para algum leitor" e que "o texto é o espaço em que sujeitos distanciados um do outro podem marcar sua presença” (COSTA VAL, 2009, p. 70).

É importante, então, que o docente conheça um pouco das representações dos alunos e do meio social e cultural no qual eles estão inseridos, a fim de que a proposta de produção textual não se distancie muito desse sujeito a ponto de inibir a escrita. Uma boa proposta textual, como propõe Costa Val (2009), deve dar suporte ao aluno, ao invés de limitá-lo; deve ser uma orientação e não uma camisa de força, a fim de que se estabeleça uma ponte entre o que os alunos já conhecem e dominam e os objetivos pedagógicos pretendidos pelo professor.

Outro ponto relevante, apontado por Costa Val (2009, p. 72), é que "o ato de produzir um texto decorre em grande medida de um ato de interpretação de uma proposta". Para muitos, o que deveria ser uma orientação que facilitasse o trabalho, transforma-se em um roteiro que deve ser rigidamente seguido. Pensar assim, condiciona o aluno a ausentarse do texto. Sobretudo se o que foi proposto carrega em si um tom de imposição argumentativa, ou ainda se traz em sua constituição um desestímulo aos interesses cognitivos e linguísticos dos estudantes. Ao abordar essas questões que envolvem a produção textual, a autora (2009, p. 45) diz que os textos escolares são feitos para a escola e, portanto, estão sujeitos a representações e condicionamentos construídos nesse espaço. É importante frisar que "o empenho em atender ao padrão ideológico escolar pode [...] acarretar prejuízos à qualidade do texto, tornando-o pouco informativo, previsível [...], repetitivo e redundante" (COSTA VAL, et. al, 2009, p. 77).

Por outro lado, uma proposta de escrita que seja bem elaborada e ofereça a possibilidade do surgimento de autoria, criará interlocução, uma vez que o aluno perceberá no professor um leitor efetivo de seu texto, alguém que se interessa pelo que é dito e pela 
forma como foi elaborado esse dizer. “Assim, vai-se configurando, nesses textos dialógicos, uma interação autor-leitor que corresponde melhor à legítima finalidade da escrita: possibilitar a interlocução a distância" (COSTA VAL, et. al, 2009, p. 84-85).

Entretanto, sabemos que o professor não pode assumir apenas o papel de leitor do texto dos seus alunos, a ele cabe também outra função, a de avaliador desse texto.

\section{O que avaliar? Forma ou conteúdo?}

Não consideramos aceitável endossar a "atitude espontaneísta de não avaliar para 'não inibir a criatividade' ou 'não desencadear uma relação negativa do aluno com a escrita"' (COSTA VAL, et. al, p. 30). Nossos textos são constantemente avaliados, também, e principalmente, fora da escola, no convívio social que estabelecemos, seja por meio da oralidade ou da escrita. Avaliar é o caminho de que dispomos para ensinar, para demonstrar o que precisa ser alterado e o que pode ser mantido. Na verdade, entendemos que os adeptos à ausência de avaliação nas produções de textos estão reagindo a uma postura muito difundida de avaliação que passa pela

constatação de que o processo de escrita, no contexto escolar, costuma ser tão carregado de sentido punitivo, que acaba produzindo sentimento de fracasso nos autores-aprendizes, já que os professores-avaliadores assumem o lugar de um revisor implacável, e não o de um leitor cooperativo. Realmente, se a produção de um texto adquire o contorno de um campo de batalha, a ideia de avaliação faz pouco sentido. (COSTA VAL, et. al, p. 30)

A avaliação, assim como a escolha da proposta textual e a produção escrita, como dito anteriormente, também é um processo que envolve a subjetividade. O professor, diante do texto, precisa tomar decisões quanto ao modo de avaliação: avaliar o quê? Forma ou conteúdo?

Parece-nos recorrente o privilégio da avaliação da forma, em detrimento do conteúdo do texto. Sendo assim, é muito difícil encontrarmos metodologias de correções que levem em conta outros procedimentos de análise que não aqueles que se voltam apenas para as questões estruturais do discurso. 
Costa Val afirma que "os conhecimentos e a voz do aluno se revelam naquilo que tem a dizer e na forma como o diz" (COSTA VAL, 2009, p. 69) e defende que, para haver a interlocução, tanto a forma quanto o conteúdo são importantes. Ideias desarticuladas, sem coesão e sem organização gramatical, mesmo que boas, serão dificilmente entendidas, comprometendo o processo comunicativo. Por outro lado, uma escrita correta em termos gramaticais, mas que apenas segue o roteiro estipulado pelo professor, tende a comprometer o sentido e a construção da autoria.

Esse equilíbrio entre forma e conteúdo no processo de produção textual se estabelece, segundo Costa Val (2009, p. 40, 41), na inter-relação entre três componentes: o contexto comunicativo, a atividade cognitiva e a verbalização, ou seja, o aluno traduz, por meio de palavras e frases, a sua intenção comunicativa.

Porém, entre a variedade linguística oral mais coloquial que o aluno usa diariamente e a oralidade e a escrita na norma padrão aprendidas na escola existe um leque de variantes, num contínuo que vai do muito informal ao muito formal. Essas variantes não são totalmente dominadas pelo discente. Assim,

É previsível que, durante o aprendizado, ele utilize, na escrita, recursos e procedimentos que domina na produção do discurso oral, sem se dar conta de que alguns deles não funcionam bem no texto escrito, sobretudo se se tratar da escrita formal. (COSTA VAL, et. al, 2009, p. 41)

Dessa forma, a produção textual reflete a oralidade cotidiana dos alunos, já que a linguagem é mediadora das interações sociais e está diretamente relacionada à posição social dos interlocutores. Costa Val (2009, p. 44) afirma que a escrita não se restringe ao domínio gramatical, que "não basta saber falar e escrever”, mas que é preciso conhecer o funcionamento comunicativo social e as regras que o regem, ou seja, "a forma como se fala ou se escreve é condicionada por elementos extralinguísticos, no plano social e histórico, no plano individual, no plano da situação comunicativa específica” (COSTA VAL, et. al, 2009, p. 44). 
Nessa direção,

se concebemos a língua como um sistema integrado pelos níveis de organização gramatical, semântico e discursivo e se consideramos o texto como resultado de suas condições de produção, nossa compreensão quanto à avaliação de um texto escrito tem de levar em conta a articulação entre os aspectos formais, semânticos e discursivos (ou comunicativos) que constituem qualquer texto. (COSTA VAL, et. al, p. 40)

Portanto, para que o processo avaliativo contribua positivamente para o aprendizado da escrita e, consequentemente, para o amadurecimento do aluno enquanto autor, é preciso um equilíbrio entre essas dimensões avaliativas.

Com efeito, avaliar forma e conteúdo estabelece a exigência de mais uma etapa substancial para o trabalho com o ensino de produção de textos: a delimitação de critérios de análise.

\section{Que critérios utilizar na avaliação?}

Delimitar critérios de análise consiste em assumir uma postura teórica, transpô-la didaticamente e, de maneira consistente, colocá-la em execução. Se entendemos que a construção de um texto é conseguida pelo entrelaçar da dimensão gramatical com a dimensão semântico-discursiva, parece-nos indiscutível a necessidade de que nosso aluno também tenha essa percepção ao ser colocado frente a frente com as instruções que lhe damos quando analisamos a produção escrita que ele realizou. Assim, no momento da correção, é preciso que avaliemos se o texto convenceu (dimensão discursiva), se o texto foi compreendido (dimensão semântica) e, ainda, se o texto apresenta estrutura adequada (dimensão gramatical). Porém, somente com o auxílio de critérios bem estabelecidos essa verificação poderá ser realizada. E esses critérios precisam ser esclarecidos, antes da produção, aos alunos, que construirão seu texto tomando-os como fundamentos para sua escrita.

Isso nos leva a uma nova pergunta que se reveste de importância para nosso trabalho: como tornar a marcação desses critérios evidente para nossos alunos? Ou seja: que estratégia(s) de correção usar no momento de avaliação dos textos? Estamos refletindo, 
nesse ponto, sobre a definição de mais um elemento desta proposta: o formato de correção a ser assumido pelo professor.

\section{Que tipo de correção utilizar?}

Sobre esse aspecto, nosso trabalho toma por base as discussões de Ruiz (2010) que, trazendo parte das análises de Serafini (1989), acrescidas de suas próprias contribuições, delimita tipos de correções que podem apresentar caráter monológico ou dialógico, no que se refere à interlocução com o texto do aluno.

Um estilo de correção tipicamente monológico corresponde ao que Serafini classifica como correção resolutiva que

[...] consiste em corrigir todos os erros, reescrevendo palavras, frases e períodos inteiros. O professor realiza uma delicada operação que requer tempo e empenho, isto é, procura separar tudo o que no texto é aceitável e interpretar as intenções do aluno sobre trechos que exigem uma correção; reescreve depois tais partes fornecendo um texto correto. Neste caso, o erro é eliminado pela solução que reflete a opinião do professor. (SERAFINI, 1989, p. 113 apud RUIZ, 2010, p. 41)

Como é possível perceber, nesse tipo de correção não há espaço para que o aluno se manifeste enquanto autor. A subjetividade e os índices de autoria, que foram discutidos anteriormente, sofrem uma fragmentação e se perdem diante das mudanças realizadas pelo professor que “atua, então, resolutivamente, nos níveis fonológico, morfológico, morfossintático e sintático-semântico do texto. Mas não atua no nível textual global” (RUIZ, 2010, p. 85). Isso nos faz perceber que aqui é desconsiderada a dimensão semântico-discursiva, por limitações impostas pelo modelo de correção assumido. E o pior, “...para o aluno, revisar respondendo a uma correção resolutiva é, no mais das vezes, uma simples tarefa de copiar a redação incluindo as alterações ortográficas e normativas já efetuadas pelo professor” (RUIZ, 2010, p. 89).

Outro modelo de correção é o chamado correção indicativa que “...consiste na estratégia de simplesmente apontar, por meio de alguma sinalização (verbal ou não, na margem e/ou no corpo do texto), o problema de produção detectado.” (RUIZ, 2010, p. 40). 
Sendo assim, essa correção não corresponde mais a uma proposta monológica de avaliação. Por ela, há uma tentativa do estabelecimento de diálogo em que o professor sinaliza o problema, esperando que o aluno compreenda essa sinalização. Pode ser feita no corpo ou na margem do texto, o que possibilita que questões de ordem semântico-discursivas também sejam apontadas, embora a incidência maior ainda seja a marcação de inadequações gramaticais.

Ainda dentro do modelo dialógico de correção, temos o que Serafini (1989) define como correção classificatória. Por meio desse tipo de correção são apontados, utilizando uma metalinguagem codificada específica, as categorias nas quais os problemas indicados no texto poderiam ser classificados (RUIZ, 2010). Essa correção aproxima-se muito da indicativa. Assim “...se, por um lado, corrigir textos de modo indicativo é codificar a forma de apontar as coisas no texto, dizendo onde está o problema na superfície da materialidade linguística, por outro, corrigir os textos de modo classificatório é codificar a forma de dizer qual é o problema" (RUIZ, 2010, p. 185). A diferença é que no modelo classificatório é necessário que o aluno domine a metalinguagem do código.

Por fim, Ruiz (2010) inclui um tipo de correção diferente daqueles descritos por Serafini (1989): a correção textual-interativa. Ela corresponde a elaboração de "bilhetes, por meio dos quais se estabelece uma interlocução não codificada com o aluno, resolvendose, indicando-se e/ou classificando-se os problemas do texto, ou ainda, atentando-se para a própria tarefa de revisão do aluno e/ou o próprio trabalho de correção do professor" (RUIZ, 2010, p. 174). Esse tipo de correção é genuinamente dialógico uma vez que que estabelece uma interlocução real com o aluno. Além disso, é capaz de abranger os problemas de ordem micro e macrotextual e representa um incentivo para que o aluno invista em uma força expressiva mais elevada no momento da reescrita.

Sendo assim, este trabalho foi desenvolvido levando em conta que o ensino de produção de textos na escola deve considerar os seguintes procedimentos:

a) A validade da proposta a ser delimitada como orientação para escrita;

b) O equilíbrio entre os elementos formais e discursivos no processo de avaliação;

c) A precisão no delineamento dos critérios que subsidiarão a análise; 
d) A funcionalidade do formato de correção a ser assumido pelo professor.

Feita a discussão acerca do embasamento teórico, passemos à metodologia utilizada na pesquisa.

\section{Caminhos metodológicos}

Realizamos, inicialmente, um aprofundamento no que diz respeito à posição teórica aqui assumida. Essas leituras correspondem a um trabalho de análise de pesquisadores que discutem a associação autor/texto/leitor na construção do processo de escrita dos alunos. Os estudos feitos, assim como a elaboração das propostas textuais aplicadas, as correções, a reescrita e as respectivas análises, foram desenvolvidas ao longo da disciplina Prática Curricular "Avaliação da Produção Escrita", ministrada na Universidade Federal de São João delRei, Minas Gerais. Assim, buscamos uma instituição escolar disposta a participar da pesquisa e em cujo calendário houvesse a possibilidade de aplicação das atividades. A parceria foi, então, firmada com a Escola Municipal Brighenti Cesare, uma instituição pública do município de São João del-Rei, com a qual trabalhamos por um período de dois meses.

Optamos, para o desenvolvimento das atividades da prática curricular, por dividir a turma de alunos da Universidade em 8 grupos, correspondentes ao número de turmas do ensino fundamental da escola parceira, que tinha duas turmas em cada ano: $6^{\circ}, 7^{\circ}, 8^{\circ}$ e $9^{\circ}$. A partir de um tema e de um gênero textual escolhidos, cada grupo elaborou uma proposta textual, em conformidade com os critérios que norteiam teoricamente a pesquisa. Essas 8 propostas foram aplicadas aos alunos, somando 3 encontros com cada turma: o primeiro, para uma aula motivadora com atividades acerca do gênero textual e do tema; o segundo, destinado à produção textual dos alunos, e o terceiro, para a reescrita dos textos, a partir das correções feitas, totalizando 24 aulas.

Selecionamos para essa pesquisa duas propostas que influenciaram negativamente a escrita dos alunos, e que, por impossibilitar o avanço para as etapas seguintes, foram reelaboradas e aplicadas no encontro destinado à reescrita. Essas duas novas propostas 
tiveram resultados opostos: uma delas se manteve negativa e a outra, ao contrário, influenciou positivamente os alunos. Analisaremos, portanto, a funcionalidade de quatro propostas, no resultado do processo de escrita, ficando as demais propostas do corpus, bastante extenso, bem como os aspectos, critérios e tipos de correção utilizados para um serem apresentados em um trabalho posterior.

Antes, porém, de iniciarmos as análises, é importante fazer algumas considerações sobre variáveis, relatadas pela supervisora da escola, que influenciaram na aplicação das propostas textuais. Além dos relatos, muito foi observado durante o período da pesquisa, nos momentos de conversas e trocas de experiências com os alunos. Essas variáveis não serão detalhadas aqui, mas consideradas como desdobramentos de dois fatores: o primeiro se refere à carência dos estudantes da Escola Brighenti Cesare, tanto material quanto afetiva: alguns vindos da Casa Lar, instituição que acolhe crianças cujos pais estão impossibilitados de cuidarem delas, seja por motivo de prisão, de alcoolismo, dependência química ou falta de moradia; outros vindos de estruturas familiares fragilizadas e em situação de vulnerabilidade social. O fato é que a maioria dos alunos não conta com o apoio da família. Pouquíssimos pais comparecem às reuniões ou quando chamados à escola. Juntamente a isso, muitos não têm computador, internet ou livros em casa para pesquisas escolares, além do livro didático oferecido pela instituição.

O outro fator, que parece estar diretamente relacionado ao anterior, diz respeito à baixa qualidade do aprendizado na escola. Segundo a supervisora, os alunos apresentam muitas deficiências, que se agravam a cada ano; além disso, não têm o hábito da escrita e da leitura, o que contribui para reforçar esse quadro. Deparamo-nos com problemas graves, como, por exemplo, um aluno não alfabetizado no $6^{\circ}$ ano, ainda em fase pré-silábica. Também observamos, no decorrer das aulas, principalmente nos $8^{\circ}$ e $9^{\circ}$ anos, o pouco conhecimento acerca dos gêneros textuais propostos e uma postura acrítica perante os temas apresentados. Tudo isso criou, em maior ou menor grau, um descompasso entre as atividades propostas, pensadas de acordo com a maturidade cognitiva esperada, e a realidade encontrada, de despreparo e falta de conhecimentos básicos por parte de muitos dos alunos. 


\section{Procedimento de análises - a primeira proposta, a segunda proposta e os textos produzidos}

\section{Proposta 1 - Trabalho com o gênero reportagem}

Elaborada para uma turma do $9^{\circ}$ ano, essa proposta foi pensada a partir do pressuposto de que a turma já conhecia o gênero reportagem. O tema escolhido foi "Exposição virtual", um assunto conhecido pela grande maioria dos adolescentes que utilizam as redes sociais como meio de interação.

Quatro atividades foram programadas para a aula motivadora: 1) exibição do vídeo "Pense antes de postar" em voz alta, feita pelos alunos da reportagem "Fala demais nas redes sociais! Cuidado com os novos criminosos online"2; 3) Conversa sobre o gênero reportagem, a fim de relembrar suas características; 4) Discussão em grupo, seguida de respostas escritas para quatro questões dadas, em folha impressa, sobre exposição virtual.

Embora a proposta tenha tratado de um tema presente no cotidiano dos alunos, a turma praticamente desconhecia as características do gênero reportagem. Por isso, tais aspectos precisaram ser retomados. A falta de domínio do gênero e o grande volume de informação apresentada prejudicaram bastante o andamento da aula e não houve tempo hábil para a aplicação de todas as atividades previstas. A dinâmica em grupo, que seria um rico momento para trocas de conhecimento e aprofundamento sobre o tema, não aconteceu.

No dia da escrita, foi entregue aos alunos, em uma folha impressa, três textos motivadores, de diferentes gêneros, que abordavam pontos de vista distintos sobre o tema "Exposição virtual”: uma charge, um gráfico e um trecho de reportagem.

A proposta pedia um texto com um mínimo de vinte e cinco linhas, o que não foi cumprido. A maioria escreveu uma média de 15 linhas, três alunos começaram apenas o

\footnotetext{
${ }^{1}$ Disponível em: https://www.youtube.com/watch?v=oI3nE_nQuBU. Acesso em: 15 abr. 2019.

2 Disponível em: https://www.nic.br/noticia/na-midia/fala-demais-nas-redes-sociais-cuidado-com-os-novoscriminosos-online/ Acesso em: 15 abr. 2019.
} 
primeiro parágrafo e um deles deixou a folha em branco. Deveriam criar uma reportagem sobre o tema discutido na aula anterior e reafirmado nos textos motivadores. Alguns copiaram partes dos textos apresentados, sem aspas ou citação. Além disso, não foi feita a adequação ao gênero reportagem por nenhum dos alunos. Nem mesmo a linguagem formal foi utilizada. O que podemos perceber são as marcas da oralidade nos textos, escritos de forma bastante coloquial. Muitos escreveram sobre situações reais, vividas por alguém próximo, como no exemplo, em que J. diz:

Já aconteceu um caso tipo esse com um primo meu pegaram a foto dele no face e esse fake ficou mexendo com todo mundo [...] O menino quando chegou na escola sem saber de nada ficou sem saber o que fazer que todo mundo tava zuando com a cara dele.

Nota-se, na materialidade dos textos, uma inconsistência linguística e discursiva bastante acentuada. Os alunos se basearam em fatos superficiais da interação social via internet, contrapondo ideias de forma bem simplificada, como em C., que escreve:

A exposição virtual por um lado é bom, pois as pessoas postam coisas legais, felizes, fotos bonitas e com cara feliz, frases importantes e tudo mais... E ao mesmo tempo coisas ruins, pois postam coisas ilegais, coisas tristes, fotos indecentes [...]A exposição virtual por um lado é bom, pois as pessoas postam coisas legais, felizes, fotos bonitas e com cara feliz, frases importantes e tudo mais... E ao mesmo tempo coisas ruins, pois postam coisas ilegais, coisas tristes, fotos indecentes $[\ldots]$

Nesse exemplo, a autora finaliza o trecho em que aponta o lado bom das redes sociais com reticências, e deixa para nós, leitores, a tarefa de preenchermos a interrogação causada pelo pensamento "e tudo mais".

Percebe-se que os textos refletem escritas bastante limitadas, por vezes incoerentes, sem coesão ou progressão, além de apresentarem muitos erros gramaticais. M., por exemplo, instiga o leitor a refletir sobre os riscos e as consequências das postagens, mas não discute ou cita nenhuma dessas consequências, seguindo de maneira linear o que foi apresentado no vídeo, durante a aula motivadora. Ela escreve:

E você já pensou o risco que você corre ao postar fotos, vídeos [...] Muitos não pensam e acabam postando coisas sem pensar e não pensam nas consequências. Entrevistando algumas pessoas 
percebi que algumas nem se quer sabia do risco ocorridos em postar fotos e lugares onde frequentam.

As análises nos mostram alunos despreparados no sentido da articulação entre os aspectos gramaticais, semânticos e discursivos da língua, além do fato de negligenciarem quase que totalmente as características do gênero reportagem. A totalidade deles escreveu uma versão argumentativa de texto. Queriam dizer. Pretendiam lidar com a própria subjetividade e encontraram essa oportunidade na proposta cujo tema - "Exposição virtual" abriu caminhos para isso. Ainda, assim, não se contrapuseram à essência temática que manifestou apenas os perigos de tal exposição. Tampouco validaram tal perigo de forma autoral. Suas vozes ficaram circunscritas à voz da proposta sem contestação e sem ampliação do que lhes foi apresentado. Não se detiveram, também, ao gênero do texto, seja por desconhecimento, seja porque ele não atendia às exigências de autoria que emergiam daqueles estudantes. Isso pode ser validado se observarmos o que ocorreu quando a proposta foi adaptada.

A segunda proposta aplicada manteve o formato de reportagem e o mesmo tema. Entretanto, dessa vez, foi apresentado a eles um texto lacunar que continha frases de introdução, desenvolvimento e conclusão, para serem completadas. Também essa proposta não funcionou e a turma pouco escreveu.

A primeira linha vinha com a palavra "Título", seguida de dois pontos; mas apenas nove, dos 22 alunos presentes, deram título ao seu texto.

Em seguida, a introdução, que começava da seguinte maneira: "Atualmente o uso das redes sociais aumentou significativamente. Segundo pesquisas, realizadas com o objetivo de listar as redes sociais mais populares entre os internautas, foram enumerados os seguintes usos:". Os dois pontos ao final indicam um acréscimo de pensamento antes de uma listagem. Essa pontuação, no entanto, foi desconsiderada por quase todos. Os alunos partiram diretamente para a escrita do nome das redes sociais mais conhecidas e não acrescentaram nenhuma outra ideia. Alguns, inclusive, elencaram essas redes sociais no formato de lista, escrevendo um nome em cada linha. Ou seja, havia agora uma organização textual que os impedia de argumentar. A organização sugeria apenas uma enumeração de dados e 
assim eles fizeram. Ou seja, o empenho em atender ao padrão proposto "pode acarretar prejuízos à qualidade do texto, tornando-o pouco informativo, previsível ou, [...], repetitivo e redundante" (COSTA VAL, et. al, 2009, p. 78).

Segue-se a esse, o parágrafo do desenvolvimento, que diz: “O uso excessivo de redes sociais vem sendo considerado uma doença, uma vez que as pessoas se tornam dependentes e fazem mal uso das mesmas, quando, por exemplo...". Nesse trecho todos os alunos desconsideraram a conjunção integrante "quando", seguida de uma proposta de exemplo, e partiram para ideias bastante distanciadas daquela que inicia o parágrafo. Citemos C., que escreve:

em vez de usar as redes sociais podem jazer varias outras coisas como exercícios jizicos como jogar bola, vôlei, basquete, ou queimada.

Ou:

O mal uso do facebook, fotos, vídeos indecentes podem causa mal pela pessoa mesma, ela pode ficar mal falada pela sociedade.

Alguns poucos parecem ter entendido a ideia a ser desenvolvida, porém não souberam estruturá-la de forma a dar sentido ao já posto. É o caso de M. N., que diz:

Quando as pessoas dorme tarde, acorda cedo as vezes dorme na aula, [...] perdem muito tempo em rede social, $[\ldots]$

Outro exemplo dessa tentativa de dar continuidade ao texto é a escrita de M.:

Chega atrasado na escola, dorme na sala de aula, fica com sono o dia inteiro. E ainda fica gerando a falta de respeito com as pessoas na redes sociais.

Quanto à parte da conclusão, foi iniciada da seguinte forma: "Sendo assim, usar a internet, redes sociais como Facebook, Twitter, WhatsApp e outros é, de certa maneira, algo que auxilia na comunicação e dia a dia das pessoas e”. Seguiu-se um espaço de duas linhas, a fim de que os alunos pudessem acrescentar outros fatores positivos das redes sociais. Logo após, foi escrita a conjunção adversativa “mas", seguida de um espaço de 12 
linhas. Quase todos deixaram a conclusão em branco. Alguns poucos escreveram uma ou duas linhas com ideias bastante desconexas e apenas dois completaram o texto de forma a dar sentido.

Ao fazermos uma análise comparativa entre essas duas propostas, aplicadas para a mesma turma do $9^{\circ}$ ano, podemos observar que muito pouco foi alterado da primeira para a segunda, no sentido da obtenção de resultados mais satisfatórios. As escritas da primeira proposta, um precioso diagnóstico da turma, nos mostraram o quão imaturos se encontravam os alunos, tanto em relação à organização gramatical, quanto em relação aos aspectos semântico-discursivos da língua. Além disso, essa proposta nos demonstra que a temática apresentada não se adequou ao gênero escolhido para abrigá-la. A sinalização de escrita de todos os estudantes exigia uma nova proposição de trabalho, a fim de que houvesse uma tentativa de resultados diferentes. Entretanto, a segunda proposta, além de não fornecer outros textos motivadores, apresentou as mesmas exigências de conhecimento linguístico e discursivo da primeira, igual número de linhas a ser preenchido e ignorou o descompasso da turma em relação ao gênero reportagem. Tratou-se, portanto, em nosso entendimento, de uma pseudossolução o que foi realizado nesse segundo momento de trabalho com os estudantes.

\section{Proposta 2 - Trabalho com os gêneros notícia e música}

Essa proposta, trabalhada com o $8^{\circ}$ ano, foi pensada em função do fácil acesso dos alunos aos dois gêneros, notícia e música, através da televisão, internet e livros didáticos, parte do cotidiano da maioria deles. Esses fatores poderiam, assim, favorecer o processo de construção subjetiva da turma.

As atividades da aula motivadora se organizaram em torno dos seguintes passos:1) leitura de um pequeno texto sobre as características do gênero notícia, para uma conversa 
sobre a estrutura desse gênero; 2) leitura da notícia "João Corrêa se prepara para ultramaratona" , a fim de que os alunos indicassem os seus aspectos estruturais; 3) leitura, audição e interpretação da música "Notícia de jornal"4, do compositor Chico Buarque, seguida da leitura da notícia "Dois tiros e dona Maria quase perde a vida", os dois gêneros com o mesmo tema. A partir dos dois textos, foi solicitado que fizessem a contraposição de um gênero ao outro e pontuassem a mudança do gênero textual notícia para o gênero textual música, por meio da análise dos elementos estruturais que apontam para essa mudança.

Na produção textual pediu-se o oposto: redigir uma notícia a partir da música "Que país é esse?”" do Legião Urbana, composta por Renato Russo. Antes de dar início à atividade, ocorreu a apresentação de um vídeo da música, seguida da leitura e interpretação da letra.

Ainda que a proposta tenha abordado gêneros e temas do cotidiano dos alunos, houve muita informação e pouco tempo para a apreensão do conteúdo. Sem uma análise mais aprofundada da letra da música com os alunos, que demonstraram não ter conhecimento nem do contexto de sua produção, nem do cenário político da atualidade, a turma ficou bastante confusa com relação à interpretação da proposta. Isso pôde ser percebido pelos resultados insatisfatórios dos textos escritos.

Dos 12 alunos presentes nessa aula, 9 escreveram menos que 15 linhas, quantidade mínima pedida, e um deixou a folha em branco. Não foi feita a adequação ao gênero notícia por nenhum aluno. Os textos são uma mistura de opinião pessoal com cópias de partes da música, e um deles é construído com rimas, pressupomos que na tentativa de aproximá-lo da canção apresentada.

Como exemplo, citemos parte do texto de G., que diz:

No Brasil tem muitas favelas muitas sujeiras ta acontecendo muitas constituição.

\footnotetext{
${ }^{3}$ Disponível em: http://www.itati.com.br/joao-correa-se-prepara-para-ultramaratona/. Acesso em: 15 abr. 2019.

${ }^{4}$ Disponível em: https://www.youtube.com/watch?v=Qz8raFQNDGI. Acesso em: 15 abr. 2019

${ }_{5}$ Disponível em: http://comunicarexpress.blogspot.com/2010/05/texto-literario-e-nao-literario.html. Acesso em: 15 abr. 2019.

${ }^{6}$ Disponível em: https://www.youtube.com/watch?v=CqttYsSYA3k. Acesso em: 15 abr. 2019.
} 
Nota-se que nesse pequeno trecho, as palavras "favela", "sujeira" e "constituição" são retiradas da música e inseridas ao texto de forma completamente descontextualizada, o que resulta em uma escrita sem sentido. E é claramente perceptível o desconhecimento da aluna acerca do significado da palavra "constituição".

Em um outro texto, B. escreve:

Nesse mês aconteceu algo no senado, que abalou a nação, Ninguém respeita a constituição, Nas favelas sujeira pra todo lado. Muitos documentos sendo falsificados "manchando papeis".

O mesmo acontece aqui: partes da música são alteradas e "coladas" de forma quase que aleatória. B. não compreende a conotação de "sujeira" na música e usa a palavra em seu sentido denotativo. Também não esclarece, por exemplo, "o que aconteceu no senado naquele mês", e se perde no próprio texto.

Confirmamos, com a prática dessa segunda proposta, assim como da primeira, analisada anteriormente, a afirmação de Costa Val: (..) o sujeito-aluno tende a silenciar-se, a ausentar-se de seu texto quando se sente constrangido a cumprir rigorosamente uma proposta, sobretudo se ela se choca com suas expectativas e possibilidades de trabalho cognitivo e linguístico (COSTA VAL, at. al, p. 76).

O silêncio apontado pela autora é visível na materialidade dos textos, pelos dizeres esvaziados de sentido. Trata-se de um silêncio que não diz, por dizer de qualquer jeito e sem qualquer preocupação em significar.

Os demais alunos também se prendem à canção, com exceção de 2, que tentam romper com esse padrão. A. escreve:

Concordo porque o Brasil está tendo varias mortes muitos assaltos e várias coisas, Mas eu nasci aqui, gosto muito dele porém está muito terrível...

G., revoltado com a música, diz:

eles falam merda e vive nele fala que ele ruim e vive nele então porque eses caras que falam do Brasil sai dele então [...] já que ele é ruim sai daki então. Na música fala Que pais e esse? Esse e o Brasil onde você mora se não gosta dele tchau.

Fato interessante ocorre quando analisamos esses dois últimos exemplos. Além de abrirem mão do gênero proposto para a escrita, ousam discordar da proposta que não põe 
em causa a situação do país. O estudante A. chega a oscilar entre concordar com a visão que a música apresenta sobre o Brasil (Concordo porque o Brasil está tendo varias mortes muitos assaltos e várias coisas [...] porém está muito terrivel] e discordar dela [Mas eu nasci aqui, gosto muito dele]. Parece alguém assustado, que tem medo de ir contra a temática proposta pela professora, mas que quer se posicionar enquanto autor. Já na opinião de G., a música não corresponde ao que ele pensa sobre o país. Para nós, há, aqui, indícios de autoria que não podem ser desconsiderados.

Nesse caso também, devido aos resultados obtidos, principalmente no que se refere à desconsideração da escrita do gênero notícia, uma nova proposta foi elaborada e aplicada na aula que seria destinada à reescrita.

Nessa segunda proposta manteve-se o gênero, mas com um tema bastante presente no cotidiano dos alunos: a dengue. Como texto motivador, foi selecionada uma notícia pequena, com letras maiores e de fácil leitura, já que a turma apresentou grande dificuldade com as questões de ordem linguística dos textos motivadores apresentados na primeira proposta.

A nova atividade trouxe uma notícia sobre testes com vacina contra a dengue, para ser lida com a turma, seguida de um texto lacunar com introdução, desenvolvimento e conclusão a ser completado. Percebemos que o investimento nessa nova proposta em relação à escrita do gênero foi muito parecido com o que foi realizado com o $9^{\circ}$ ano. Entretanto, mudanças substanciais ocorrem tanto em relação à temática quanto aos aspectos didáticos e metodológicos utilizados na aula motivadora de escrita.

Essa nova proposta influenciou positivamente a escrita dos alunos. Notou-se mais fluência nos textos. Com exceção de um aluno, que deixou a folha em branco, todos escreveram. As lacunas foram preenchidas de forma a dar sentido ao texto. Atribuímos isso ao reflexo das vivências dos estudantes e à maior objetividade do tema, que facilitou a descrição em formato de notícia. Afinal, "mesmo que o aluno não tenha consciência, nos momentos em que fala ou escreve, ele faz escolhas e toma decisões (cujas possibilidades são condicionadas por processos históricos e sociais que envolvem a língua e as instituições), 
em função de seu envolvimento na situação comunicativa” (COSTA VAL, et. al, 2009, p. 70-71).

O texto traz a seguinte introdução: "A dengue é uma doença transmitida pelo mosquito Aedes Aegypti. Atualmente, o que se vê no Brasil é...”. Ao darem sequência ao parágrafo, os alunos abordam vários aspectos relacionados à dengue, numa escrita marcada pelo cotidiano, como se segue:

hospitais cheios, postos de saúde lotado, pois ele traz enfraquecimento, hemorragia e pode levar a morte.

\section{$\mathrm{Ou}$}

mortes, muita água parada, geralmente quando chove muito, nas casas, nas ruas ficam vários potes, latinhas, pneu e etc.

Ou ainda:

muitas pessoas morrendo por causa da doença, muitas pessoas internadas, muita água parada, pessoas de cama sem forças para levantar.

Outros ainda elencaram as doenças transmitidas pelo mosquito, falaram de crianças e idosos com dengue, da microcefalia, enfim, percebeu-se que o tema estimulou a produção e que os alunos conheciam o assunto proposto.

O parágrafo de desenvolvimento do texto diz: "Por outro lado, o povo brasileiro permanece"... Isso também é completado adequadamente, pela maioria da turma, e temos escritas como:

sem mudar seus hábitos para acabar com os criatórios do mosquito."

$\mathrm{Ou}$

deixando água parada, não se prevenido desse mal.

E, na conclusão, cujo início é: "Sendo assim," nota-se também a subjetividade do aluno:

o melhor que nós podemos fazer é deixar os agentes de saúde entrar e seguir os conselhos que eles falam para gente. 
Em comparação com os textos escritos na primeira proposta, nos quais percebe-se o distanciamento da turma e o conflito entre não saber o que dizer e ter que dizer, essa segunda proposta apresenta textos nos quais nota-se a facilidade dos alunos na abordagem do tema e a presença da autoria.

\section{Considerações finais}

Essa pesquisa, na qual refletimos sobre os caminhos metodológicos do professor como mediador da produção escrita dos alunos, nos trouxe resultados bastante significativos. O corpus analisado aqui, um pequeno recorte do rico material que colhemos, nos mostrou claramente como uma proposta textual pode influenciar negativa ou positivamente a produção escrita do aluno; fato relevante a ser considerado pelo docente no momento de planejar e avaliar as suas estratégias pedagógicas.

A escola é um espaço de interação social real e não apenas um espaço de preparação para o mundo, para o "lá fora". Sob esse viés, atividades de escrita pensadas de forma a motivar interações verdadeiras e não apenas processos automatizados, são, geralmente, bem-sucedidas. Quando o aluno recebe uma proposta que dialoga com seu universo cognitivo e linguístico, ele se sente estimulado a escrever. Vimos, nos pressupostos teóricos apresentados e na aplicação prática em sala de aula, a importância dessa interlocução, o que nos faz afirmar, em acordo com Costa Val (2009), que é a partir do diálogo proposto que o processo de autoria pode ser de fato construído, porque motivado.

Vale ressaltar que um trabalho de retrospecção, como o que se delineou neste texto, a partir de agora, instiga-nos a cultivar, também, e necessariamente, uma postura de prospecção: o caminho trilhado aponta para qual horizonte? Dito de outra forma, entendemos que a argumentação que ora apresentamos tentou trazer à tona um passado de ações (e pretensões) que se querem coerentes; entretanto, essa mesma argumentação não pode desconsiderar a existência de reflexões diferentes daquelas aqui apresentadas, uma vez que se configura como um trabalho de memórias, mas também de expectativas e apontamentos. 


\section{TEXT PRODUCTION: \\ IN SEARCH OF CONSTRUCTION OF AUTHORSHIP}

ABSTRACT: This work has arisen from the need to take a closer look at the methods taken by the teacher as a mediator in the students' written production process. Thence, it is organized around the practice development related to teaching text production to primary school students, through work with textual genres. Hence, it aims to accomplish a didactic transposition of the theoretical assumptions about textual production, in order to mobilize the teaching pedagogical practice. From this perspective, it works with the aspect that the teacher mediation is really important so that the studentwriter's voice appears in his writing. The corpus under analysis is composed of texts written and rewritten by eighth and ninth grade students of primary school at the State School Brighenti Cesare, in São João del-Rei, MG, and was part of the activities of the discipline called Curricular Practice Evaluation of Written Production, offered by the undergraduate degree in Languages at the Federal University of São João del-Rei. This paper had as main theoretical support the Costa Val's (2009) and Ruiz's (2010) studies, and as an analysis snippet sought to reflect to what extent the writing proposals applied encourage the subjectivity of the student-writer.

KEYWORDS: Construction of authorship; Teaching; Text production.

\section{REFERÊNCIAS}

BENVENISTE, E. Problemas de lingüística geral II. Campinas: Pontes, 1989.

BRASIL. Secretaria de Educação Fundamental. Parâmetros curriculares nacionais: terceiro e quarto ciclos do ensino fundamental - Língua Portuguesa. Brasília: MEC/SEF, 1998.

BRASIL. Base Nacional Comum Curricular (BNCC). Educação é a Base. Brasília, MEC/CONSED/UNDIME, 2017. Disponível em: 568http://basenacionalcomum.mec.gov.br/images/BNCC_publicacao.pdf. Acesso em: 02 jun. 2017.

COSTA VAL, M. G. Avaliação do texto escolar-professor-leitor/aluno-autor. São Paulo: Autêntica/ CEALE, 2009.

GALLO, S. L. Discurso da escrita e do ensino. Campinas: Editora da Unicamp, 1992.

ORLANDI, E. P. Discurso e leitura. São Paulo: Cortez, 1993.

RUIZ E. D.: Como corrigir redaçôes na escola. São Paulo: Contexto, 2010.

SERAFINI, M. T. Como escrever textos. Trad. Maria Augusta Bastos de Mattos. São Paulo: Globo, 1989.

Recebido em: 15/05/2020.

Aprovado em: 04/06/2020. 